\title{
IUFOST2006/42
}

\section{Can We Reduce World Hunger by $50 \%$ in only Nine More Years?}

\author{
K. Marsh \\ Woodstock Institute for Science in Service to Humanity, 102B Ole Towne Square, Central, SC, 29630, \\ United States of America \\ ken@drkenmarsh.com
}

Nine years remain before the deadline for the first Millennium Development Goal (MDG) to reduce world hunger by $50 \%$ by 2015. The World Food Summit:five years later was held in 2002 because this hunger reduction target would not be met with "business as usual" and current estimates still predict falling short of the target. Presentations on food security at the World Food Congresses X and XII suggested that food science and technology can offer post harvest options which can be added to the traditional agricultural production emphasis to help meet the MDG.

This paper combines ideas and suggestions discussed in the previous world food congresses and presents the modified program and justification for the modifications resulting from Congress XII. The program incorporates post harvest assessments and action to enhance food delivery, primarily in rural regions. Presentation of this program in various countries in the developing world led to invitations to visit post harvest institutions in the host countries in which commendable work is performed with substantial impact on food availability. After visiting multiple post harvest institutes, it became evident that these institutes had measured post harvest losses and found appropriate technologies to reduce those losses. It also became evident that duplicate efforts were being performed in different countries. These realizations spawned a proposed new program to survey post harvest institute programs, identify successes and failures, and seek ways to share the successes and bring additional resources to "fix" the failures. Substantial expertise exists among IUFoST Adhering Bodies, and taping this resource could enhance the country efforts and potentially promote international cooperation and coordination.

This oral presentation will present the various programs, suggest how IUFoST delegates can offer their expertise to support post harvest efforts, and present a plan to meet the Millennium goal for hunger reduction. 